\title{
Serological evidence and factors associated with porcine toxoplasmosis in three villages of Fara's division in Burkina Faso
}

\author{
Laibané Dieudonné DAHOUROU ${ }^{*}$, Oubri Bassa GBATI², Arnaud Rayangnéwêndé \\ Stéphane TAPSOBA ${ }^{3}$, Saandi MOINA RIZIKI ${ }^{2}$ and Amadou TRAORE ${ }^{3}$ \\ IInstitut des Sciences de l'Environnement et de Développement Rural (ISEDR), Université de Dédougou \\ (UDDG), BP 176, Dédougou, Burkina Faso. \\ ${ }^{2}$ Ecole Inter-Etats des Sciences et Médecines Vétérinaires de Dakar (EISMV), BP 5077, Dakar, Sénégal. \\ ${ }^{3}$ Institut National de l'Environnement et de Recherches Agricoles (INERA) BP 8645, Ouagadougou, \\ Burkina Faso. \\ *Corresponding author; E-mail: d_dahourou@yahoo.fr; Tel: +22670653744
}

\section{ACKNOWLEDGEMENTS}

We are grateful to the Parasitology Service of Inter States School of Sciences and Veterinary Medicine, Dakar, Senegal for supporting the present study.

\begin{abstract}
Porcine toxoplasmosis is a worldwide zoonosis. This study was conducted to establish evidence of toxoplasmosis and its associated factors among pigs in three villages of Balés province, Burkina Faso. Serums samples were collected from 182 pigs and data was collected on farmers' sociodemographics, origin (village) of pigs, pigs' sex, age, breed and keeping systems through a household questionnaire interview. Serum samples were analyzed using indirect ELISA targeting IgG antibodies to Toxoplasma gondii. Results of the study showed an overall sero-prevalence of $16.5 \%$ (95\% CI: $11.1 \%$ - 21.9\%). The sero-prevalence was higher in Toné $(23.1 \%$; 95\% CI: $12.8 \%-33.3 \%$ ) and Kabourou (20.7\%; 95\% CI: $10.3 \%-31.1 \%)$ compared to Sadon Bobo (5.1\%; $95 \%$ CI: $0 \%-10.7 \%)(p=0.01)$. It was also higher in pigs older than 12 months $(23.2 \% ; 95 \%$ CI: $14.9 \%-31.5 \%)$ compared to pigs less than 12 months $(8.4 \%$; 95\% CI: $02.4 \%-14.4 \%)(p=0.00731)$. During rainy season, tethered pigs $(7.1 \%$; CI95: $0.40 \%-13.8 \%)$ were less infected than housed pigs $(20.6 \%$; $95 \%$ CI: $11.1 \%-21.9 \%)$ $(p=0.02)$. Multivariate logistic regression model shows that pigs older than 12 months were more likely to get infected compared to pigs less than 12 months old $(\mathrm{OR}=2.58 ; 95 \% \mathrm{CI}=1.00-6.62 ; p=0.04)$. These results provided evidence for the presence of $T$. gondii in pigs in this area.
\end{abstract}

(C) 2020 International Formulae Group. All rights reserved.

Keywords: Burkina Faso, pigs, Toxoplasma gondii, seroepidemiological studies, zoonosis.

\section{INTRODUCTION}

Toxoplasmosis is caused by Toxoplasma gondii. It is major zoonosis disease of medical and socio-economic importance (Sonar and Brahmbhatt, 2010).
Felidae familly, especially the cat, are the only known definitive hosts of the parasite (Dubey et al., 2012) releasing millions of parasite oocysts in the environment. These oocysts after sporulation can maintain their infectivity for 
several months in water and soil and are responsible for infestation of intermediate hosts including human and other animals like sheep, goats, pigs, chickens (Buxton et al., 2007). Intermediate hosts could become infected through consumption of food or water contaminated with oocysts (Dubey and Jones, 2008). Ingestion of raw or undercooked meat of infected animals is the most common way of human infection (Belloco et al., 2016; De Berardinis et al., 2017). The transmission risk could be higher with sheeps' and pigs' meat as T. gondii infection is common in those animals. However, infection of cattle, horses and water buffaloes with $T$. gondii is less common than infection in sheep or pigs (Hill and Dubey, 2002). There is also congenital transmission in human which lead to serious neurological or ocular disorders with cardiac and brain abnormalities such as hydrocephalus, mental retardation, seizures or fetal mortality (Jones et al., 2001; Remington et al., 2006). The disease is usually asymptomatic in immunocompetent individuals but can lead to serious complications in immunosuppressed individuals. It is common in pregnant women in Burkina Faso (Bamba et al., 2017b) and can lead to abortions. In rural communities of Burkina Faso, pig meat is mostly consumed boiled (Ngowi et al., 2017; Dahourou et al., 2018). So, consumption of pork could be at risk for $T$. gondii transmission to humans, especially when the meat is undercooked (Dubey, 2009). In Burkina Faso, like in other African countries, pigs are mainly reared in traditional way and free ranging is very common in this pigs' management system (Mopate et al., 2011; Kiendrebeogo et al., 2012; Djimenou et al., 2017). However, this type of breeding system is associated with higher risk of toxoplasmosis in pigs (Stelzer et al., 2019).

Studies on animal toxoplasmosis, mainly on pigs, are scarce in West Africa. Studies were carried out in Burkina Faso and Côte d'Ivoire (Pangré et al., 2009; Bamba et al., 2016) but have only focused in pigs' in slaughterhouses located in the cities. Otherwise no sero epidemiological study, focused on porcine toxoplasmosis, has been carried out in rural area in Burkina Faso. Hence, this study aimed at evaluating the serological evidence of porcine toxoplasmosis and its associated factors among free roaming pigs in three villages of Burkina Faso.

\section{MATERIALS AND METHODS Study area}

The study took place in province of the Balés, located in the Boucle du Mouhoun region. Three villages, in Fara division, were selected for this study. The villages are located at $60 \mathrm{~km}$ from national road one, on the regional road 11 beetwen Poura Carrefour village and the border with Ghana. Populations of this area are mostly animists with an important pig population except for Kabourou where we have many Muslims, with a small pig population. The area has a tropical climate with two seasons. The rainy season from May to September with an average rainfall of $871 \mathrm{~mm}$. The dry season is between October and April.

In the study area, there is no data on pig numbers and pigs' husbandry practices depend on the season. During rainy season, pigs are tethered or kept confined (housed) in pigsties; while during dry season, pigs are left scavenging for food. According to veterinary services in this area, pigs' main reported diseases are African swine fever, porcine cysticercosis and gastro intestinal parasitic infections.

\section{Sample size and pig selection}

At the beginning, blood samples collection was designed for porcine cysticercosis prevalence study in this province. During field activities, the presence of toxoplasmosis has been suspected. As samples collected were enough for a study on toxoplasmosis, serum collected was used to assess the evidence of toxoplasmosis in pigs to increase knowledge on zoonosis in the study area.

Sampling size was calculated using Epitools Epidemiological calculators with the following formula: $\mathrm{N}=\left(\mathrm{Z}^{2} * \mathrm{P}(1-\mathrm{P})\right) / \mathrm{e}^{2}$; where $\mathrm{N}$ is the sample size, $\mathrm{Z}$ is the value from standard normal distribution corresponding to 95\% confidence level, $\mathrm{P}$ is the expected 
prevalence and $\mathrm{e}$ is the precision. The precision was set at $7 \%$ and expected prevalence was estimated to $28.8 \%$ (Bamba et al., 2017b) and pig population of 270504 pigs in the region (Institut National de la Statistique et de la démographie, 2016). The minimum sample required for this study was 162 , but 182 samples were sampled. From each animal, blood was drawn for serum harvesting. In each village, households were randomly selected from all pig-keeping households and each selected household were visited and one pig were randomly selected.

\section{Questionnaire survey}

A questionnaire was administered to each farmer whose animal was included in the study to collect information on potential associated factors to pigs' infection with $T$. gondii. Data on farmer gender and their experience with pig husbandry, pigs' sex, age and breed, pig keeping type was collected. Data was recorded on sheets and linked to the animal biodata. Same predictors of sero-positivity to porcine cysticercosis were used in the risk factor analysis of $T$. gondii.

\section{Serological analysis}

Pig sera samples were tested using commercial indirect ELISA Kits (ID Screen ${ }^{\circledR}$ Toxoplasmosis Indirect Multi-Species from ID Vet Innovative Diagnostic, Montpellier, France) which detects Toxoplasma $s p$ specific IgG antibodies in pigs' sera. This ELISA test used microplates precoated by Toxoplasma gondii specific $\mathrm{P} 30$ antigen. The aim of the reaction is to build antigen-antibody-conjugate complex which make a reaction with a substrate and produce a coloration detected by the measurement of optical densities. Optical densities (OD) were read at $450 \mathrm{~nm}$. The test was validated if the mean value of the positive control O.D. (ODPC) is greater than 0.350 (ODPC >0.350) and the ratio of the mean O.D. values of the positive and negative controls (ODPC and ODNC) is greater than 3.5 (ODPC/ODNC >3.5). According to the manufacturer's recommendation, sera or meat juice with $\mathrm{S} / \mathrm{P} \%$ less than or equal to $40 \%$ are considered negative, between 40 and $50 \%$ are considered doubtful and greater than or equal to $50 \%$ are considered positive. Samples with S/P \% greater than or equal to $200 \%$ are considered as acute infection. Doubtful samples were repeated for certainty.

\section{Statistical analysis}

Data was transferred on Microsoft (2007) Excel sheet, and statistical analysis was performed using STATA 13. Apparent seroprevalences were calculated and expressed in percentage with $95 \%$ confidence interval $(\mathrm{CI})$. Descriptive statistics were used to report demographic characteristics of respondents, as well as pig characteristics. Univariate analysis was carried out on each identified potential risk factors independently. Significant variables to univariate analysis at $\mathrm{P} \leq 0.1$ were included in a multivariable logistic regression model to compute adjusted odds ratios (AOR) at 95\% CI. Tests for significance of associations were performed at significance level of 0.05 .

\section{RESULTS}

Sero-prevalence of toxoplasmosis in pigs is summarized in table 1 . The overall seroprevalence was $16.5 \%$ (95\% CI: $11.1 \%$ $21.9 \%$ ) with $40 \%$ of acute toxoplasmosis. This prevalence was significantly associated with village, pig age and keeping type during rainy season. The highest prevalence was found in Toné village $(23.1 \%$; $95 \%$ CI: $12.8 \%-33.3 \%)$ and the lowest at Sadon Bobo village (5.1\%; 95\% CI: $0-10.7 \%$ ). There was also a difference in prevalence between village $(p=0.01)$. The prevalence was higher in older pigs (more than 12 months) $(23.2 \%$; 95\% CI: $14.9 \%-31.5 \%)$ compared to younger pigs (less than 12 months) $(8.4 \%$; 95\% CI: $2.4 \%-$ $14.4 \%)(p=0.007)$. Prevalence was higher in confined pigs during rainy season $(20.6 \%$; $95 \%$ CI: $13.5 \%-27.6 \%)$ compared to tethered (7.1\%; 95\% CI: $0.40 \%-13.8 \%)(p=0.02)$.

The prevalence was $10.6 \%$ (95\% CI: $11.3 \%-22.3 \%$ ) in animals kept by women while none animal kept by men was infected in the present study ( $p=0.43$ ). Pigs that belong to farmers with longer experience in pig keeping (more than five years) were more infected then pigs that belong to farmers with short 
experience in pig husbandry (Table 1). The infection was higher in females (19.8\%; 95\% CI: $12.5 \%-27.05 \%)$ than in males $(10.6 \%$; 95\% CI: $3.2 \%-18.02 \%)(p=0.107)$. Variation was noted on prevalence regarding pigs' breed and the prevalence was $18.8 \%$ (95\% CI: $12.5 \%$ $-25.1 \%$ ) and $6.1 \%$ (95\% CI: $0 \%-14.3 \%)$ in local and mixed pigs respectively $(p=0.07)$.

Univariate logistic regression revealed that different factors were associated with $T$. gondii infection. Pigs which were more than 12 months were 3.28 times more likely to be infected by $T$. gondii than those less than 12 months (Table 2) $(p=0.01)$. Pigs tethered were also, less likely to be infected with $T$. gondii $(\mathrm{OR}=0.29 ; \mathrm{CI} 95=0.09-0.89 ; p=0.03)$ than confined pigs during rainy season. Also, Pigs from Sadon bobo village were less likely to be infected with $T$. gondii $(\mathrm{OR}=0.18$; CI95: 0.04 $-0.65 ; p=0.009)$ when compared with pigs from other villages (Table 2).

After multivariable regression analysis, only pig age was associated to infection with $T$. gondii. Pigs which were more than 12 months were 2.58 times more likely to have $T$. gondii than animals less than 12 months (Table 3) $(p=0.04)$.

Table 1: Descriptive characteristics of farmers, sampled pigs with associated $T$. gondii seroprevalences in Balés provinces, Burkina Faso.

\begin{tabular}{|c|c|c|c|c|}
\hline Variables & Category & $\mathbf{n}$ & Seroprevalence and $95 \% \mathrm{CI}$ & p-value \\
\hline \multirow{3}{*}{ Village } & Kabourou & 58 & $20.7(10.3-31.1)$ & \multirow{3}{*}{0.01} \\
\hline & Sadon Bobo & 59 & $05.1(0-10.7)$ & \\
\hline & Toné & 65 & $23.1(12.8-33.3)$ & \\
\hline \multirow{3}{*}{ Farmer experience } & Less than 5 years & 10 & $10(0-28.6)$ & \multirow{3}{*}{0.84} \\
\hline & $\begin{array}{l}\text { Between } 5 \text { and } 10 \\
\text { years }\end{array}$ & 72 & $16.7(8.1-25.3)$ & \\
\hline & Above 10 years & 100 & $17(9.6-24.4)$ & \\
\hline \multirow{2}{*}{ Farmer gender } & Men & 3 & 0 & \multirow{2}{*}{0.43} \\
\hline & Women & 179 & $16.8(11.3-22.3)$ & \\
\hline \multirow{2}{*}{ Pig sex } & Male & 66 & $10.6(3.2-18.02)$ & \multirow{2}{*}{0.107} \\
\hline & Female & 116 & $19.8(12.5-27.05)$ & \\
\hline \multirow{2}{*}{ Pig breed } & Local & 149 & $18.8(12.5-25.1)$ & \multirow{2}{*}{0.07} \\
\hline & Mixed & 33 & $06.1(0-14.3)$ & \\
\hline \multirow{2}{*}{ Age class } & [0 - 12 months $]$ & 83 & $08.4(2.4-14.4)$ & \multirow{2}{*}{0.00731} \\
\hline & $>12$ months & 99 & $23.2(14.9-31.5)$ & \\
\hline \multirow{2}{*}{ Pigs living area } & Piggeries & 126 & $20.6(13.5-27.6)$ & \multirow{2}{*}{0.02} \\
\hline & Tethered & 56 & $7.1(0.40-13.8)$ & \\
\hline Total animal sampled & - & 182 & $16.5(11.1-21.9)$ & \\
\hline
\end{tabular}

$\mathrm{n}$ : number of sampled animals for the category; CI: Confident Interval 
Table 2: Univariable logistic regression analysis of potential explanatory of $T$. gondii infections in pigs in Balés province, Burkina Faso.

\begin{tabular}{llll}
\hline Variables & \multicolumn{1}{c}{ Category } & Crude OR and 95 \% CI & p-value \\
\hline \multirow{2}{*}{ Village } & Kabourou & $0.86(0.36-02.05)$ & 0.750 \\
& Sadon Bobo & $0.178(0.04-0.65)$ & 0.009 \\
& Toné & 1 & \\
Farmer experience & Less than 5 years & 1 & 0.593 \\
& Between 5 and 10 years & $1.80(0.20-15.56)$ & 0.574 \\
Farmer gender & Above 10 years & $1.84(0.21-15.52)$ & 0.991 \\
& Men & $0.00(0.00-10.9)$ & \\
Pig sex & Women & 1 & 0.11 \\
Pig breed & Male & $0.479(0.19-1.18)$ & \\
Female & Local & 1 & 0.09 \\
Pigs living area & Mixed & 1 & 0.01 \\
\hline
\end{tabular}

OR: Odds Ratio ; CI : Confident Interval

Table 3: Factors associated with Toxoplasma gondii infection in pigs in Balés Province, Burkina Faso.

\begin{tabular}{lllll}
\hline Variable & Category & Adjusted OR & 95\% CI for OR & P-Value \\
\hline \multirow{2}{*}{ Village of origin } & Toné & 1 & & \\
& Sadon Bobo & 0.33 & $0.04-1.46$ & 0.12 \\
& Kabourou & 0.89 & $0.33-1.93$ & 0.62 \\
Pig Age Class & {$[0-12$ months $]$} & 1 & & \\
\multirow{2}{*}{ Pig sex } & $>12$ months & 2.58 & $1.00-6.62$ & 0.04 \\
& Male & 0.69 & $0.26-1.81$ & 0.46 \\
Pigs' living area & Female & 1 & & \\
& Piggeries & 1 & & 0.72 \\
\hline
\end{tabular}

OR : Odds Ratio; CI : Confident Interval 


\section{DISCUSSION}

Toxoplasmosis was described in animals and mainly in pigs over the world (Dubey, 2009) and in Africa (Tonouhewa et al., 2017). This first serological evidence of $T$. gondii on pigs, from Balés Province, reported a seroprevalence of $16.5 \%$ (CI95: 11.1 21.9\%). In Burkina Faso, Bamba et al. (2016) and Bamba et al. (2017b) have respectively reported a prevalence of $29 \%$ and $28.8 \%$ in pork in an abattoir survey in Bobo Dioulasso. This indicate evidence of porcine toxoplasmosis in pigs in Burkina Faso and regarding this situation, pork eaters could be at risk for toxoplasmosis. Furthermore, in Burkina Faso, the prevalence of toxoplasmosis in pregnant women is $31.1 \%$ and consumption of meat including pork was reported as risk factor of human infection (Bamba et al, 2017a).

In Côte d'Ivoire, Pangré et al. (2009) found a prevalence of $8.8 \%$ in an abattoir survey on pork. Arko-Mensahet al. (2000) in Ghana, Gebremedhin et al. (2015) in Ethiopia and Hove et al. (2005) in Zimbabwe have reported prevalence of $39 \%, 32.1 \%$ and $3.51 \%$ respectively. In Nigeria, Obijiaku et al. (2017) and Onyiche and Ademola (2015) have reported $4.4 \%$ and $29.14 \%$ respectively. In the others part of world, Hill et al (2010) reported a prevalence of $2.6 \%$ in United States and Alvarado-esquivel et al. (2011) found $12.7 \%$ in Mexico. In Asia, $27 \%$ has been reported in pigs by Zhou et al. (2010) in China. Lopes et al. (2013) in Portugal and Garcia-Bocanegra et al. (2010) in Spain have reported 9.8\% and 19\% respectively. Such seroprevalence variations might be linked to differences in climatic conditions (altitude, rainfall, soil type, temperature) and animals management systems (intensive, extensive) and also pigs access to cats scat (Dubey, 2009; Innes, 2010).

According to different explanatory variables, the infection of pigs was associated with location (village), pigs age and pigs living area. The higher seroprevalence in Toné and Kabourou villages, compared to Sadon Bobo village $(\mathrm{P}<0.05)$ could be associated with high density of cats observed in Toné and Kabourou (personal observations). In different studies carried out in United States and The
Netherlands, cats' access to pigs and the number of cats in farms lead to high prevalences of $T$. gondi iinfection in pigs (Dubey, 2009). Pigs' age has been found to be a risk factor for porcine toxoplasmosis in different studies (Arko-Mensah et al., 2000; Gebremedhin et al., 2015). The higher seroprevalence of toxoplasmosis in pigs older than 12 months compared to pigs less than 12 months might be due to the longer contact time of older animals with a potentially infected environment containing $T$. gondii oocysts and/or tissue cysts (Villari et al., 2009). The study found that pigs kept in piggeries during rainy season were more infected with T. gondii compared to those that were tethered. During rainy season, cats get access to piggeries for food and might exposed pigs to $\mathrm{T}$. gondii oocysts though their infected scats. In Togo, neighboring country of Burkina Faso, Degbe et al. (2018) found that a high proportion of cats around Lomé release oocysts in their scats.

Some limitations have been noted for this study. During field activities, many associated factors were not added on the survey questionnaire for the identification of risk factors. This suggests that further studies are needed at national level to identify on animal level risk factor of toxoplasmosis on animal.

\section{Conclusion}

Toxoplasmosis is an important zoonotic disease which affects many animal species and human. The present study, conducted in a division of Burkina Faso, reported a prevalence of $16.5 \%$ for porcine toxoplasmosis and has highlighted that pigs older than 12 months were more likely to be infected with $T$. gondii compared to those less than 12 months. As human toxoplasmosis transmission through infected meat and regarding the important prevalence, it is necessary for health sector stakeholders to implement sensitization actions in this area.

\section{COMPETING INTERESTS}

Authors declare that there is no competing interests. 


\section{AUTHORS' CONTRIBUTIONS}

The study has been designed by LDD, OBG and AT. SMR and ARST collected data on the field and made laboratory analysis. LDD made statistical analysis and proposed the draft of the manuscript. All authors reviewed the manuscript before submission.

\section{ACKNOWLEDGEMENTS}

We would like to thank sincerely laboratory and field techniciansfor their help during this study. We also thank local populations and veterinary local staff for their collaboration and help during field activities. We are grateful to Mr OUATTARA for his great help during sample collection.

\section{REFERENCES}

Alvarado-Esquivel C, García-Machado C, Alvarado-Esquivel D, González-Salazar AM, Briones-Fraire C, Vitela-Corrales J, Villena I, Dubey JP. 2011. Seroprevalence of Toxoplasma gondii infection in domestic pigs in Durango State, Mexico. J. Parasitol., 97(4): 616619. DOI: 10.1645/GE-2755.1.

Arko-Mensah J, Bosompem KM, Canacoo EA, Wastling JM, Akanmori BD. 2000. The seroprevalence of toxoplasmosis in pigs in Ghana. Acta Trop., 76(1): 27-31. DOI: 10.1016/S0001-706X(00)00085-1.

Bamba S, Halos L, Tarnagda Z, Alanio A, Macé $P$, Moukoury S, Sangaré I,Guiguemdé R, Costa JM, Bretagne S. 2016. Seroprevalence of Toxoplasma gondii and direct genotyping using mini sequencing in free-range pigs in Burkina Faso. Int. J. Food Microbiol., 230: 10-15. DOI: 10.1016/j.ijfoodmicro.2016.04.016

Bamba S, Cissé M, Sangaré I, Zida A, Ouattara S, Guiguemdé RT. 2017a. Seroprevalence and risk factors of Toxoplasma gondii infection in pregnant women from Bobo Dioulasso, Burkina Faso. BMC Infect. Dis., 17(1): 482. DOI: 10.1186/s12879-017-2583-6.

Bamba S, Bazié WW, Lingani M, Sourabié Y, Sombié I, Ndiaye JL, Tarnagda Z, 2017b. Seroepidemiology of Toxoplasma gondii infection among slaughtered pigs, cattle and goats for human consumption in Bobo-Dioulasso, Burkina Faso. $J$. Parasitol. Vector Biol., 9(8): 106-110. DOI : 10.5897/JPVB2017.0290.

Belluco S, Mancin M, Conficoni D, Simonato G, Pietrobelli M, Ricci A. 2016. Investigating the determinants of Toxoplasma gondii prevalence in meat: a systematic review and metaregression. PloS one, 11(4): e0153856. DOI: 10.1371/journal.pone.0153856.

Buxton D, Maley SW, Wright SE, Rodger S, Bartley P, Innes EA. 2007. Toxoplasma gondii and ovine toxoplasmosis: new aspects of an old story. Vet. Parasitol., 149(1-2): 25-28. DOI: 10.1016/j.vetpar.2007.07.003.

Dahourou LD, Gbati OB, Millogo A, Dicko A, Roamba CR, Pangui LJ. 2018. Analysis of the knowledge, attitudes and practices of populations in four villages of the Boucle du Mouhoun Region (Burkina Faso) regarding Tania solium life cycle. Health, 10(1): 95-106. DOI: 10.4236/health.2018.101008.

De Berardinis A, Paludi D, Pennisi L,Vergara A. 2017. Toxoplasma gondii, a foodborne pathogen in the swine production chain from a European perspective. Foodborne Pathog. $\quad$ Dis., 14(11): 637-648. DOI: 10.1089/fpd.2017.2305.

Degbe M, Tete-Benissan A, Maman H, Kulo A, Batawui B, Aklikokou K, Gbeassor M. 2018. Epidémiologie de la toxoplasmose au Togo: facteurs de risque dans la capitale et ses agglomérations. Int. J. Biol. Chem. Sci., 12(1) : $\quad 479-490 . \quad$ DOI : 10.4314/ijbcs.v12i1.37.

Djimenou D, Adoukonou-Sagbadja H, Koudande DO, Chrysostome CAAM, Hounzangbe-Adote SM, Agbangla C. $2017 . \quad$ Caractéristiques sociodémographiques des éleveurs de porcs (Sus Scrofa domesticus) et structure du cheptel porcin au Sud du Bénin. Int. J. Biol. Chem. Sci., 11(5): 2177-2193. DOI : 10.4314/ijbcs.v11i5.19.

Dubey JP, Jones JL. 2008. Toxoplasma gondii infection in humans and animals in the 
United States. Int. J. Parasitol., 38(11): 1257-1278.

DOI: 10.1016/j.ijpara.2008.03.007.

Dubey JP. 2009. Toxoplasmosis in pigs-the last 20 years. Vet. Parasitol., 164(2-4) : 89103. DOI: 10.1016/j.vetpar.2009.05.018.

Dubey JP, Tiao N, Gebreyes WA, Jones JL. 2012. A review of toxoplasmosis in humans and animals in Ethiopia. Epidemiol. Infect., 140(11): 1935-1938.

DOI: 10.1017/S0950268812001392.

García-Bocanegra I, Simon-Grifé M, Dubey JP, Casal J, Martín GE, Cabezón O, Perea A, Almería S. 2010. Seroprevalence and risk factors associated with Toxoplasma gondii in domestic pigs from Spain. Parasitol. Int., 59(3): 421-426. DOI: $10.1016 /$ j.parint.2010.06.001.

Gebremedhin EZ, Kebeta MM, Asaye M, Ashenafi H, Di Marco V, Vitale M. 2015. First report on seroepidemiology of Toxoplasma gondii infection in pigs in Central Ethiopia. BMC Vet. Res., 11(1): 59. DOI: 10.1186/s12917-015-0384-y.

Hill D, Dubey JP. 2002. Toxoplasma gondii: transmission, diagnosis and prevention. Clin. Microbiol. Infect., 8(10): 634-640. DOI: 10.1046/j.14690691.2002.00485.x.

Hill DE, Haley C, Wagner B, Gamble HR, Dubey JP. 2010. Seroprevalence of and risk factors for Toxoplasma gondii in the US swine herd using sera collected during the National Animal Health Monitoring Survey (Swine 2006). Zoonoses Public Health, 57(1): 53-59. DOI: 10.1111/j.1863-2378.2009.01275.x.

Hove T, Lind P, Mukaratirwa S. 2005. Seroprevalence of Toxoplasma gondii infection in domestic pigs reared under different management systems in Zimbabwe. Onderstepoort J. Vet. Res., 72(3): 231-237. DOI: 10.4102/ojvr.v72i3.200.

Innes EA. 2010. A brief history and overview of Toxoplasma gondii. Zoonoses Public Health, 57(1) : 1-7. DOI: 10.1111/j.18632378.2009.01276.x.
Institut National de la Statistique et de la démographie 2016. Annuaire statistiques 2015, INSD: Ouagadougou.

Jones JL, Lopez A, Wilson M, Schulkin J, Gibbs R. 2001. Congenital toxoplasmosis: a review. Obstet. Gynecol. Surv., 56(5): 296-305. DOI: 10.1097/00006254-200105000-00025.

Kiendrebeogo T, Logtene YM, Kondombo SR, Kabore-Zoungrana CY. 2012. Characterization and importance of pig breeds in the pork industry of the zone of Bobo-Dioulasso (Burkina Faso, West Africa). Int. J. Biol. Chem. Sci., 6(4): 1535-1547. DOI: 10.4314/ijbcs.v6i4.13.

Lopes AP, Dubey JP, Neto F, Rodrigues A, Martins T, Rodrigues M, Cardoso L. 2013. Seroprevalence of Toxoplasma gondii infection in cattle, sheep, goats and pigs from the North of Portugal for human consumption. Vet. Parasitol., 193(1-3): 266-269. DOI: 10.1016/j.vetpar.2012.12.001.

Mopate LY, Kabore-Zoungrana CY, Facho B, 2011. Structure des troupeaux et performances des élevages porcins de la zone de N'Djaména au Tchad. Int. J. Biol. Chem. Sci., 5(1): 321-330. DOI: 10.4314/ijbcs.v5i1.68108.

Ngowi H, Ozbolt I, Millogo A, Dermauw V, Somé T, Spicer P, Jervis LL, GanabaR, Gabriel S, Dorny P, Carabin H. 2017. Development of a health education intervention strategy using an implementation research method to control taeniasis and cysticercosis in Burkina Faso. Infect. Dis Poverty, 6(1): 95. DOI: 10.1186/s40249-017-0308-0.

Obijiaku IN, Ornguga N, Adikwu AA. 2017. Seroprevalence of Toxoplasma gondii infection in slaughtered pigs in Makurdi, Nigeria. Sokoto J. Vet. Sci., 15(3): 91-94. DOI: $10.4314 /$ sokjvs.v15i3.13.

Onyiche TE, Ademola IO. 2015. Seroprevalence of anti-Toxoplasma gondii antibodies in cattle and pigs in Ibadan, Nigeria. J. Parasitic Dis., 39(2): 309-314. DOI: $10.1007 / \mathrm{s} 12639-013-$ 0350-1. 
Prange A, Perret C, Marie JL, Calvet F, Halos L, Boireau P, Davoust B. 2009. Toxoplasmosis: a survey on meat products in Côte d'Ivoire. Med. Trop., 69(6): 629-630.

Remington JS, Klein JO, Wilson C, Baker CJ. 2006. Infectious Diseases of Fetus and Newborn Infant. Elsevier-Saunders: Philadelphia.

Sonar SS, Brahmbhatt MN; 2010. Toxoplasmosis: an important protozoan zoonosis. Vet. World, 3(9): 436-439. DOI: 10.5455/vetworld.2010.436-439.

Stelzer S, Basso W, Silván JB, Ortega-Mora LM, Maksimov P, Gethmann J, Conraths FJ, Schares G. 2019. Toxoplasma gondii infection and toxoplasmosis in farm animals: Risk factors and economic impact. Food Waterborne Parasitol., 15: e00037.

DOI:
Tonouhewa ABN, Akpo Y, Sessou P, Adoligbe C, Yessinou E, Hounmanou YG, Assogba MN, Youssao I, Farougou S. 2017. Toxoplasma gondii infection in meat animals from Africa: Systematic review and meta-analysis of seroepidemiological studies. Vet. World, 10(2): $194 . \quad$ DOI: 10.14202/vetworld.2017.194-208.

Villari S, Vesco G, Petersen E, Crispo A, Buffolano W. 2009. Risk factors for toxoplasmosis in pigs bredin Sicily, Southern Italy. Vet. Parasitol., 161(1-2): 1-8. DOI: 10.1016/j.vetpar.2009.01.019.

Zhou DH, Liang R, Yin CC, Zhao FR, Yuan ZG, Lin RQ, Song HQ, Zhu XQ. 2010. Seroprevalence of Toxoplasma gondii in pigs from southern China. J. Parasitol., 96(3): 673-674. DOI: $10.1645 /$ ge2416.1 . 